\title{
A Phosphorus-Nitrogen Flame-retardant: Synthesis and Application in Cotton Fabrics
}

\author{
Qiang-Lin LI ${ }^{1,2}{ }^{*}$, Fang-Qian HUANG ${ }^{2}$, Yu-Jun WEI ${ }^{2}$, Ju-Zhen WU ${ }^{1}$, Zheng ZHOU ${ }^{1}$, \\ Guo LIU ${ }^{1,3}$
}

\author{
${ }^{1}$ Chengdu Technological University, Institute for Environmental Governance and Intelligent Monitoring, Chengdu \\ Sichuan 611730, China \\ ${ }^{2}$ Chengdu Textile College, Chengdu Sichuan 611731, China \\ ${ }^{3}$ Chengdu University of Technological, Chengdu Sichuan 610059, China
}

crossref http://dx.doi.org/10.5755/j01.ms.24.4.18606

Received 17 July 2017; accepted 25 December 2017

\begin{abstract}
Cotton textiles with high air permeability, good hygroscopicity and good soft-feeling due to be natural cellulose fabrics, but their high flammability greatly limit its applications; fire-retardant finishing of cotton fabrics can impart good flame retardant properties. In this research, a novel phosphorous-nitrogen flame retardant (FR), poly-(imino-4-amino- 1,3,5-triazin-2,6-imino-(3-oxopropyl)-N-phenylphosphinamido) (PCEPAM) was synthesized with 2-carboxyethyl(phenyl)phosphinic acid (CEPPA) and melamine (MA). Its structure was characterized by FTIR, ${ }^{1} \mathrm{H}-$ NMR, and the thermal performance was analyzed by TGA-DSC. Cotton fabrics were treated via pad-dry-cure process with PCEPAM. The surfaces of treated fabrics and the combustion residue were characterized by SEM. The fire behavior was performed by limited oxygen index (LOI) and vertical burning test. The LOI of FR fabric is more than $28.5 \%$ after washing once. The thermal stability and surfaces of the combustion residue of the fabrics were investigated by TG and SEM, respectively. The results show that PCEPAM is not only an effective FR but also a good char-forming agent for the cotton fabric.

Keywords: flame retardant, cotton fabrics, synthesis, finishing, fire behavior.
\end{abstract}

\section{INTRODUCTION}

Textile is widely applied to clothing, knitwear and home textiles because of outstanding softness and breathability. However, due to its highly flammability, it was essential and crucial to impart the flame retardancy to fabrics [1]. Flame retardant (FR) textile can slow down fire spread rate, reduce fire hazards, extend escape time, and thereby protect people's lives and property [2]. Thus, a study on flame retardant fabrics is not only of great significance to the development of the apparel industry and decorative materials, but also of an urgent challenge [3]. In our previous research, we developed a crosslinkable containing-phosphorus FR with active group [4, 5], a series of phosphorus-nitrogen synergist FRs [6,7], and an excellent insolubility phosphorus-nitrogen-silicone synergist FR [8]. Usually, flame retardant (FR) finishing of fabric is an economic and practical choice, especially, natural fiber textile. Despite many FR finishing methods have been reported [9-11], no good practical finishing method for many fabrics has been developed up to now. It is well known that phosphorus and nitrogen elements, which are of good synergistic effect, are effective FR element for cellulose and polyethylene terephthalate (PET) materials [12]. In this research, a novel phosphorusnitrogen flame retardant (PCEPAM) is synthesized with 2-carboxyethyl(phenyl)phosphinic acid (CEPPA) and melamine (MA) (Scheme 1). And it is characterized by FT-IR and ${ }^{1} \mathrm{H}-\mathrm{NMR}$. Its thermal property, flame retardancy

\footnotetext{
* Corresponding author. Tel.: +086-87996647; fax: +086-87996647

E-mail address: lqlxp1010@163.com (Q.L. Li)
}

are performed by Simultaneous Thermal Analyzer (Thermal Gravimetric Analysis/Differential Scanning Calorimeter, TGA-DSC), vertical burning and limited oxygen index (LOI). And other properties such as durability of treated fabrics with the FR coating agent are investigated, too.

\section{MATERIALS AND METHODS}

\subsection{Materials}

A cotton plain woven fabric weighing $80 \mathrm{~g} / \mathrm{m}^{2}$ was supplied by Sichuan Cotton Mill Ltd. The 2-carboxyethyl(phenyl)phosphinic acid (CEPPA), melamine (MA) were supplied by Chengdu Changzheng Chemistry industry Company. The acrylic emulsion and the thickener were commercial products supplied by Chengdu Guixi Construction Chemical Company.

\subsection{Synthesis and characterization of PCEPAM}

CEPPA (21.42 g, $0.10 \mathrm{~mol}$ ) was added to a glass flask containing $100 \mathrm{~mL}$ water and equipped with a stirrer, thermometer, and condenser. The mixture was heated to boiling and stirred untill completely dissolved. Then melamine $(12.61 \mathrm{~g}, 0.10 \mathrm{~mol})$ was added into the mixture. The mixture was reacted for $20 \mathrm{~min}$ to produce white precipitate. Then the product was cooled to room temperature, filtered and dried to obtain an intermediate $\mathrm{CEPAM}^{+}$, white solid. The intermediate was added into a evaporating dish, heated to completely melted and stirred until turning into light yellow viscous melt, about $15 \mathrm{~min}$, no $\mathrm{H}_{2} \mathrm{O}$ vapor was released, and the reaction was complete, 
the yellow product was obtained. The solid product was dispersed in $100 \mathrm{~mL} 70{ }^{\circ} \mathrm{C}$ hot water, stirred about $15 \mathrm{~min}$. Finally, through filtration, washing 3 times with hot water and drying, a Novel phosphorus-nitrogen FR, PCEPAM, a pale yellow solid was obtained (yield $86.3 \%$ ).

The FTIR spectrum of PCEPAM was obtained with an FTIR spectrophotometer (Nicolet 6700, Thermo Nicolet, Waltham, MA) with a potassium bromide pellet technique, and the 1H-NMR spectra were obtain on an NMR spectrophotometer (Varian INOVA-400, Varian, Palo Alto, CA) with hexadeuterated dimethyl sulfoxide (DMSO) as a solvent. The data of FTIR $\left(\mathrm{KBr}, \mathrm{cm}^{-1}\right)$ : 3360, 3161, 3052, 2952, 2843, 1669, 1506, 1435, 1440, 1256, $1129,1037,959,785,751,732,697,521$. The data of ${ }^{1} \mathrm{H}-$ NMR (400 MHz, DMSO, TMS, ppm): 7.8-7.6(5H), $6.6(8 \mathrm{H}), 4.6(2 \mathrm{H}), 1.4-1.3(4 \mathrm{H})$.

\subsection{Treatment process}

FR bath was prepared with $30 \%$ PCEPAM (w/w) and $70 \%$ acrylic emulsion (w/w), then controlled viscosity (about $1500 \mathrm{mPa} \cdot \mathrm{s}$ ) with thickener and water, and the content of PCEPAM was $45 \%$ in the dry coatings. The treatment process of cotton fabrics with FR bath was showed in Fig. 1. The cotton fabrics were immersed in FR bath (the bath ratio was 1:20) to give an approximately $100 \%$ wet pickup regulated by padding. After double-dipdouble-nip, the fabrics samples were pre-baked at $105{ }^{\circ} \mathrm{C}$ for $5 \mathrm{~min}$ and then were cured at $160{ }^{\circ} \mathrm{C}$ for $3 \mathrm{~min}$. Part of the fabric samples tested directly without washing, and the others were washed at $40{ }^{\circ} \mathrm{C}$ in distilled water for $10 \mathrm{~min}$ and finally dried at $90{ }^{\circ} \mathrm{C}$, and then tested. The add-on $(\%)$ of coating was calculated from the Eq. 1 .

$$
\text { add }- \text { on } \%=\frac{w_{\mathrm{t}}-w_{\mathrm{o}}}{w_{\mathrm{t}}} \times 100 \%,
$$

where $w_{\mathrm{o}}$ and $w_{\mathrm{t}}$ are the weights of the T/C fabrics before and after blade coating with FR coating agent, and $w_{\mathrm{n}}$ denotes the weights of the T/C fabrics after washing $n$ times, respectively.

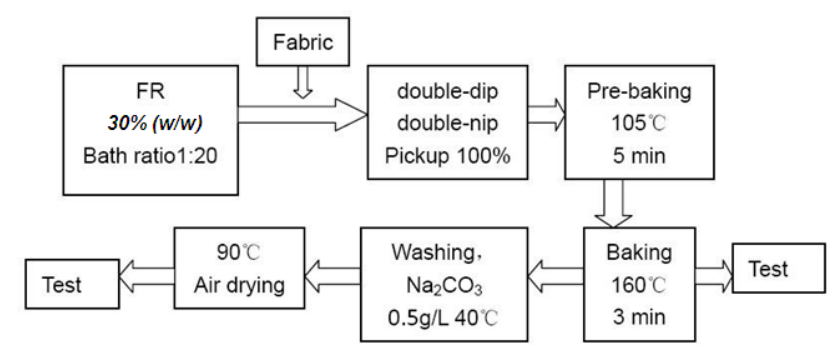

Fig. 1. Schematic diagram of flame-retardant finishing process with PCEPAM

\subsection{Combustion performance}

The LOI values of the samples were measured on an oxygen index flammability gauge (HC-2C, Nanjing Shangyuan Analytical Instruments, Nanjing, China) according to ASTM D 2863-97. The vertical burning test was conducted on a CZF-2 type instrument (Jiangning, China) according to ASTM D 6413-99. This testing method measures the vertical flame resistance of textiles in general, including after-flame time $\left(t_{\text {flame }}\right)$, that is, the length of time the material continues to burn after removal of the burner after a $12 \mathrm{~s}$ ignition time; afterglow time $\left(t_{\text {glow }}\right)$, that is, the length of time the material glows after the flame extinguishes; and char length $\left(L_{\text {char }}\right)$, that is, the distance from the edge of the fabric that is exposed to the flame to the end of the area affected by the flame.

\subsection{Thermal properties}

TGA-DSC of FR, treated and untreated fabrics were conducted on a Synchronization Thermal Analysis STA 449C (Netzsch, German) at a heating rate of $10^{\circ} \mathrm{C} / \mathrm{min}$. Aluminum sample pans were used. The samples $(5-7 \mathrm{mg})$ were heated in the analyzer at temperatures ranging from 40 to $580{ }^{\circ} \mathrm{C}$ under $\mathrm{N}_{2}$ at a flow rate of $45 \mathrm{~mL} / \mathrm{min}$.

\subsection{Measurements of the surface morphology of the treated fabrics}

The surface morphology of the untreated and treated cotton fabrics before and after washing were investigated by SEM (XL30 ESEM-TMP, Philips-FEI, Eindhoven, Netherlands) at $10 \mathrm{kV}$. The residues of the untreated and treated cotton fabrics obtained from the fabric after combustion in air were also investigated by SEM. All samples were coated with gold before examination.

\section{RESULTS AND DISCUSSION}

\subsection{Synthesis and characterization of PCEPAM}

PCEPAM was prepared via the reactions of forming salt and dehydration. First, the $-\mathrm{NH}_{2}$ of melamine were formed ammonium salts with the $\mathrm{COOH}$ and $\mathrm{P}-\mathrm{OH}$ of CEPPA molecular in aqueous solution. Then, the ammonium salts were dehydrated to produce oligomer of phosphoramidite and amide.

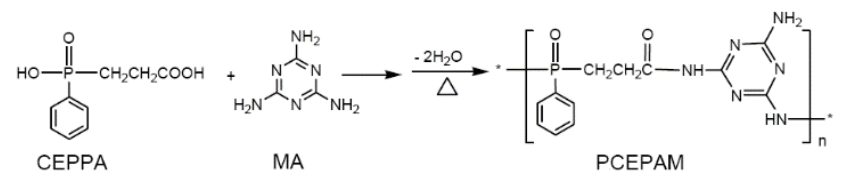

Scheme 1. Synthetic route of PCEPAM

The FTIR spectrum of PCEPAM is shown in Fig. 2. The N-H and $\mathrm{NH}^{+}$stretching vibration were around $3360 \mathrm{~cm}^{-1}$ and $3161 \mathrm{~cm}^{-1}$, respectively; and $\mathrm{CH}_{2}$ stretching vibration were showed at the 2952 and $2843 \mathrm{~cm}^{-1} ; \mathrm{C}=\mathrm{O}$ and $\mathrm{P}=\mathrm{O}$ stretching vibration were found at $1669 \mathrm{~cm}^{-1}$ and $1256 \mathrm{~cm}^{-1}$, respectively; stretching vibrations of $\mathrm{N}-\mathrm{C}(=\mathrm{O})$ and $\mathrm{N}-\mathrm{P}(=\mathrm{O})$ appeared at $1129 \mathrm{~cm}^{-1}$ and $697 \mathrm{~cm}^{-1}$, respectively. Also, the bands at 3052, 1508, 785 and $732 \mathrm{~cm}^{-1}$ were the characteristic absorbing peaks of the benzene ring.

The ${ }^{1} \mathrm{H}-\mathrm{NMR}$ spectrum of PCEPAM shows (Fig. 3 a) the aromatic protons resonated at $7.8(\mathrm{~d}, \mathrm{~J}=7.2 \mathrm{~Hz}, 2 \mathrm{H}$, $\left.\operatorname{arC}-\mathrm{H}_{\mathrm{o}}\right), 7.7\left(\mathrm{~s}, 1 \mathrm{H}, \operatorname{arC}=\mathrm{H}_{\mathrm{p}}\right)$, and $7.6 \mathrm{ppm}(\mathrm{d}, \mathrm{J}=7.1 \mathrm{~Hz}$, $2 \mathrm{H}$, arC- $\mathrm{H}_{\mathrm{m}}$ ). The chemical shifts of $\mathrm{CH}_{2}$ were found at 1.4 $\left(\mathrm{d}, \mathrm{J}=8.2 \mathrm{~Hz}, 2 \mathrm{H}, \mathrm{P}-\mathrm{CH}_{2}\right)$ and $1.3 \mathrm{ppm}(\mathrm{d}, \mathrm{J}=7.4 \mathrm{~Hz}, 2 \mathrm{H}$, $\left.\mathrm{CH}_{2}-\mathrm{C}=\mathrm{O}\right) . \quad 4.39-4.29 \mathrm{ppm}\left(\mathrm{m}, 2 \mathrm{H}, \quad \mathrm{CH}_{2}-\mathrm{C}=\mathrm{O}\right)$, and $4.1 \mathrm{ppm}(\mathrm{s}, 4 \mathrm{H}, \mathrm{OH})$. The chemical shifts of the active hydrogen, $-\mathrm{NH}_{2}$ and $-\mathrm{NH}$-, resonate at 6.6 and $4.6 \mathrm{ppm}$. The ${ }^{13} \mathrm{C}-\mathrm{NMR}$ spectrum of PCEPAM shows (Fig. $3 \mathrm{~b}$ ) the carbon resonation of triazine is $183(\operatorname{ar} C-\mathrm{NH}-\mathrm{C}=\mathrm{O}), 178$ 
$(\operatorname{ar} C-\mathrm{NH}-\mathrm{P}=\mathrm{O})$ and $154 \mathrm{ppm}\left(\operatorname{ar} C-\mathrm{NH}_{2}\right)$, carbon resonation of $C=\mathrm{O}$ is $174 \mathrm{ppm}$, phenyl carbons resonated at $134(\operatorname{ar} C$ $\mathrm{P}), 132\left(\operatorname{ar} C_{\mathrm{m}}\right), 130\left(\operatorname{ar} C_{\mathrm{o}}\right)$, and $127 \mathrm{ppm}(\operatorname{arC} \mathrm{p})$, The chemical shifts of $\mathrm{CH}_{2}$ were found at $25\left(\mathrm{P}-\mathrm{CH}_{2}\right)$ and 26 $\operatorname{ppm}\left(\mathrm{CH}_{2}-\mathrm{C}=\mathrm{O}\right)$.

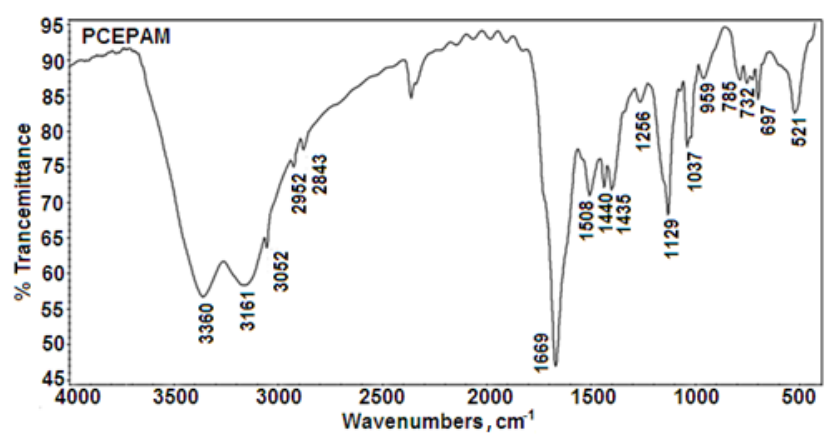

Fig. 2. FTIR spectra of PCEPAM
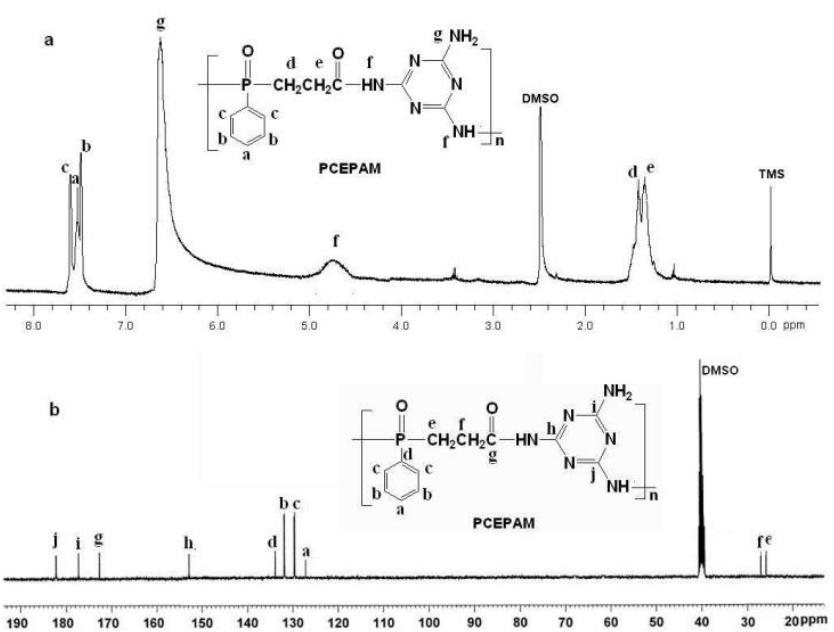

Fig. 3. ${ }^{1} \mathrm{H}-\mathrm{NMR} \mathrm{a}-13 \mathrm{C}-\mathrm{NMR}$; $\mathrm{b}-$ spectra of PCEPAM

\subsection{Micrographs of treated fabrics}

The cotton fabrics were treated via pad-dry-thermosol finishing using coating agent containing PCEPAM. As shown in the SEM photographs in Fig. 4, the surface of the untreated cotton fabrics (Fig. 4 a) was smooth and relatively neat. As far as the treated cotton fabrics (Fig. 4 b) were concerned, the surface became rough, many granular species packed on the fiber, and FRs filled in between fibers. After it was washed once (Fig. 4 c), the fiber was still somewhat shaggy, and the surface of fiber is covered by an uniform and compact layered coatings, and a small amount of flame-retardant particles are fixed onto the surface of fabric by physical absorption. These results indicate that FRs have been fixed onto fiber.

\subsection{Thermal stability of CEPAM+ and PCEPAM}

TGA-DSC thermograms of $\mathrm{CEPAM}^{+}$and PCEPAM are shown in Fig. 5 and the relevant thermal decomposition data are listed in Table 1. It is interesting that the curve 1 $\left(\mathrm{CEPAM}^{+}\right)$shows two stages but the curve 3 (PCEPAM) only one continuous decomposition stage, and the second stage of curve 1 is markedly similar with curve 3 . So in the curves 1 , the first stage, which is the dehydration to PCEPAM stage, appeared in $127 \sim 151^{\circ} \mathrm{C}$. $T_{1 \max }$ is found at $146{ }^{\circ} \mathrm{C}$, and weight loss is $7.4 \%$; the second decomposition stage is in $229-542{ }^{\circ} \mathrm{C}$, which is a continuous decomposition stage of PCEPAM, $T_{2 \max }$ is found at $318{ }^{\circ} \mathrm{C}$, and weight-loss is $42.4 \%$. The degradation of PCEPAM is shown in curve 3 , which is a continuous and long decomposition stage in $230-540{ }^{\circ} \mathrm{C}$. $T_{\max }$ is found at $317^{\circ} \mathrm{C}$, and the weight loss is $39.5 \%$. Finally, the residue of CEPAM ${ }^{+}$and PCEPAM at $580{ }^{\circ} \mathrm{C}$ is $50.0 \%$ and $54.5 \%$, respectively. It is can be seen that there are appeared many endothermic peaks in DSC curve 2 and curve 4 . In the second decomposition stage of $\mathrm{CEPAM}^{+}$, its DSC curve 2 is also very much similar with curve 4, which showed this stage is just the decomposition of PCEPAM. This result indicates that the decomposition of PCEPAM occurred via multi-stage, which can play a good endothermic role during fire-retarding. And it may greatly inhibit the decomposition of substrate polymer and decrease the concentration of incombustible gas [13].
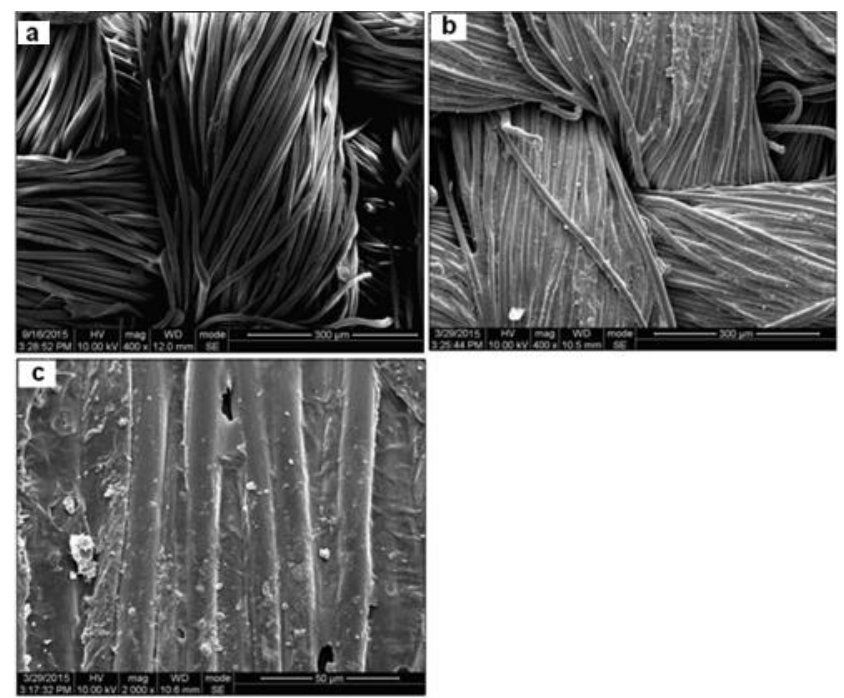

Fig. 4. SEM micrographs $a-400 X$ of surface of blank fabric, $b$ 400X and $c-2000 \mathrm{X}$ of surface of treated fabrics by PCEPAM after washing once

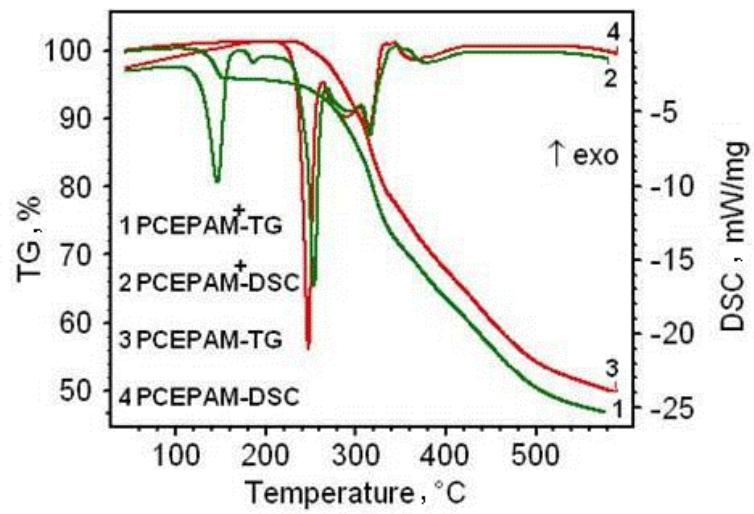

Fig. 5. TGA-DSC curves of CEPAM ${ }^{+}$and PCEPAM in $\mathrm{N}_{2}$ at heating rate of $10^{\circ} \mathrm{C} / \mathrm{min}$

Degradation of FR cotton fabrics are shown in Table 1 and Fig. 6, too. It is well known that $T_{\text {on }}$ of effective FR must be close to or slightly lower than that of substrate polymer, namely, FR begins to decompose to play a flameretarding role before substrate material pyrolysis. Moreover, the ideal FR acts on flame retardancy during the whole pyrolysis process of the matrix material [14]. 
Table 1. TGA data of CEPAM ${ }^{+}$, PCEPAM, cotton and FR-cotton

\begin{tabular}{|c|c|c|c|c|c|c|c|c|c|c|}
\hline \multirow[b]{2}{*}{ Sample } & \multirow[b]{2}{*}{$T_{\mathrm{on}},{ }^{\circ} \mathrm{C}$} & \multirow[b]{2}{*}{$\begin{array}{l}580{ }^{\circ} \mathrm{C} \\
\text { residue, \% }\end{array}$} & \multicolumn{4}{|c|}{ First weight-loss stage } & \multicolumn{4}{|c|}{ Second weight-loss stage } \\
\hline & & & $\begin{array}{c}T_{\text {on }}{ }^{\mathrm{a}}- \\
T_{\text {end }}{ }^{\mathrm{b}},{ }^{\circ} \mathrm{C}\end{array}$ & $\begin{array}{c}T_{\max { }^{c}}{ }^{\circ} \\
\text { C }\end{array}$ & $\begin{array}{l}v_{\max }{ }^{d}, \\
\% / \text { min }\end{array}$ & $\begin{array}{c}W_{\text {loss }}, \\
\%\end{array}$ & $\begin{array}{c}T_{\text {on }}-T_{\text {end }}, \\
{ }^{\circ} \mathrm{C}\end{array}$ & $\begin{array}{c}T_{\max }, \\
{ }^{\circ} \mathrm{C}\end{array}$ & $\begin{array}{c}v_{\max }, \\
\% / \text { min }\end{array}$ & $\begin{array}{c}W_{\text {loss, }}, \\
\%\end{array}$ \\
\hline CEPAM $^{+}$ & 127 & 50.0 & $127-151$ & $\overline{146}$ & $\overline{2.45}$ & $\overline{7.4}$ & $229-542$ & 318 & 4.55 & 42.4 \\
\hline РCЕРАМ & 230 & 54.5 & - & - & - & - & $230-540$ & 317 & 4.54 & 39.5 \\
\hline Cotton & 303 & 21.4 & - & - & - & - & $303-380$ & 362 & 26.52 & 71.3 \\
\hline FR-cotton & 252 & 44.0 & $252-355$ & 326 & 9.41 & 32.9 & $355-447$ & 410 & 1.74 & 12.3 \\
\hline $\begin{array}{l}{ }^{\mathrm{a}} T_{\text {on }} \text { denotes } \\
{ }^{\mathrm{b}} T_{\max } \text { denote } \\
{ }^{\mathrm{c}} v_{\max } \text { denote } \\
{ }^{\mathrm{d}}\end{array}$ & $\overline{\text { nper }}$ & d denot & & & & & & & & \\
\hline
\end{tabular}

Table 2. Flame retardancy of treated fabrics with PCEPAM undergoing different times washing

\begin{tabular}{|c|c|c|c|c|c|c|}
\hline $\begin{array}{c}\text { Washing } \\
\text { times }\end{array}$ & \multirow{2}{*}{ FR add-on, $\%$} & $\begin{array}{c}\text { Burning } \\
\text { rank }\end{array}$ & \multirow{2}{*}{ LOI, $\%$} & \multicolumn{3}{|c|}{ Vertical burning test } \\
\cline { 5 - 7 } & & Char length, mm & After-flame time, $\mathrm{s}$ & After-glow time, $\mathrm{s}$ \\
\hline blank & 0 & Failed & $19.2 \pm 0.2$ & N.R. $^{\mathrm{a}}$ & N.R. & N.R. \\
0 & 28.5 & B1 & $35.2 \pm 0.1$ & 38 & N.O. ${ }^{\mathrm{b}}$ & N.O. \\
1 & 23.9 & B2 & $28.6 \pm 0.2$ & 52 & 2.0 & 0 \\
5 & 18.4 & Failed & $26.2 \pm 0.1$ & 162 & 5.3 & 0 \\
10 & 15.2 & Failed & $25.4 \pm 0.2$ & T.D. ${ }^{\text {c }}$ & N.R. & N.R. \\
\hline
\end{tabular}

So PCEPAM may be an efficient FR for cotton fabric, because its $T_{\text {on }}$ is lower than that of cotton $\left(T_{\text {on }}=303{ }^{\circ} \mathrm{C}\right)$, and its temperature range of decomposition $\left(T_{\text {on }}-\right.$ $\left.T_{\text {end }}=230{ }^{\circ} \mathrm{C}-540{ }^{\circ} \mathrm{C}\right)$ contains that of cotton fabric $\left(T_{\text {on }}-\right.$ $\left.T_{\text {end }}=303{ }^{\circ} \mathrm{C}-380{ }^{\circ} \mathrm{C}\right)$. As can be seen that the degradation of cotton fabrics becomes from one weightloss stage to two weight-loss stage after treated with PCEPAM coating, and $T_{\max }$ of FR fabric is decreased from $362{ }^{\circ} \mathrm{C}$ to $326{ }^{\circ} \mathrm{C}$, its maximum weight-loss rate is highly reduced from $26.52 \% / \mathrm{min}$ to $9.41 \% / \mathrm{min}$. The residue at $580{ }^{\circ} \mathrm{C}$ is greatly increased $22.6 \%$ than blank cotton. So the result again indicates that PCEPAM is an excellent charring agent for cotton.

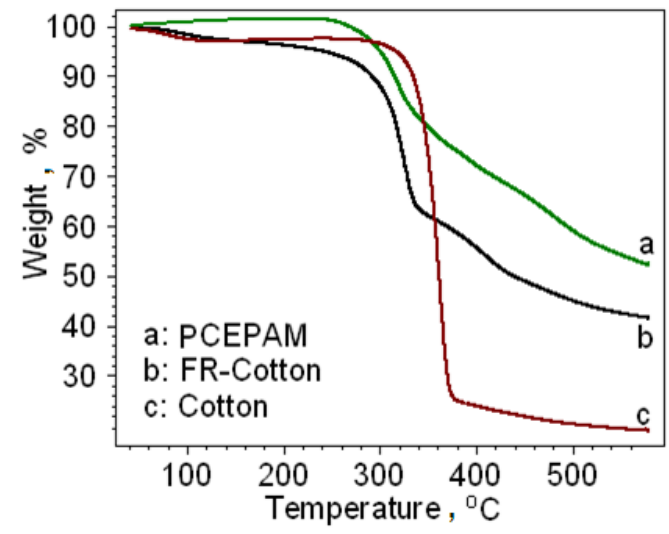

Fig. 6. TGA curves: $a-P C E P A M ; b-F R-c o t t o n ; c-c o t t o n$ in $\mathrm{N}_{2}$ at heating rate of $10{ }^{\circ} \mathrm{C} / \mathrm{min}$

\subsection{Burning performance}

To evaluate flame retardancy of the treated fabrics, LOI and vertical burning test are used, and the data are given in Table 2. The add-on of FR coating is $28.5 \%$ without washing. Its LOI is more than $35.2 \%$ (LOI of blank is $19.2 \%$ ). LOI decreases to $28.6 \%$ after washing once. The vertical burning test shows that FR-fabrics are promptly self-extinguished after igniting. And the maximum damaged length ( $\left.L_{\text {damage }}\right)$ is only $52 \mathrm{~mm}$, and the burning rank reaches B2. LOI after washing 5 and 10 times are 26.2 and 25.4, respectively.

As can be seen from Fig. 7 a and b, during the vertical burning test, a little smoke produces while igniting, and the fire is self-extinguishes after igniting $12 \mathrm{~s}$, carbon length is only $52 \mathrm{~mm}$. The coated fabric is charred significantly (Fig. 7 d), but the side of the without igniting was remaining gray, and the original appearance of fabric is maintained completely (Fig. 7 c). The surfaces of char layer of coated side are uneven but smooth (Fig. $7 \mathrm{~d}$ ), which may contribute to inhibit the exchange of combustible gas and oxygen to prevent continuous burning.
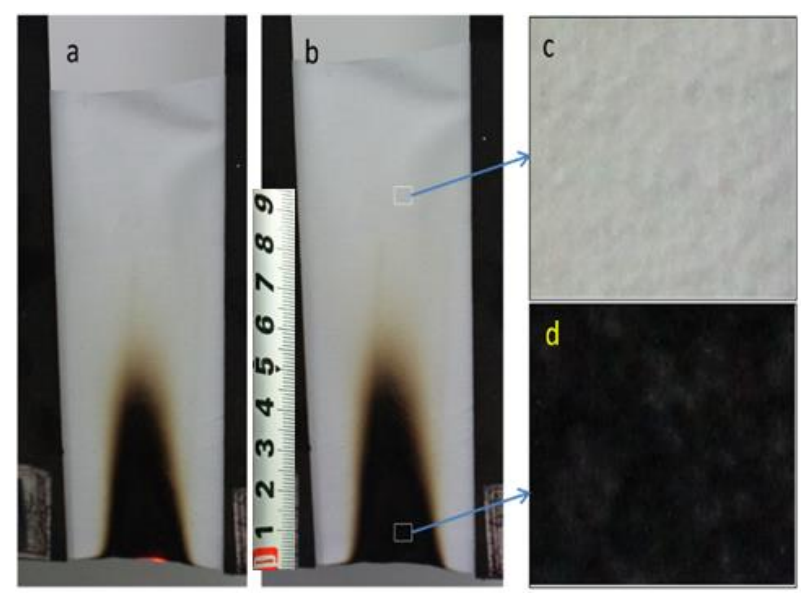

Fig. 7. Digital photos of vertical burning test: a-igniting 12s; $\mathrm{b}$-after self-extinguishment; $\mathrm{c}$-original FR-fabrics without burning; $\mathrm{d}$ - the char layer after burning

\subsection{Morphology of residue after fabric burning}

The residue of treated fabrics retains the origin morphology of fabric (Fig. 8 a) after vertical burning test. Fig. $8 \mathrm{~b}$ shows that the fibers are adhered together except for some gas holes on the surface. The residue of a yarn is 
showed in Fig. 8c, which is a uniformly distributed sandylike char structure. Fig. $8 \mathrm{~d}$ shows that the char is discontinuous and snowflake-like as a result of enhancing char-forming effect of FR. By forming a barrier between flame and the underlying fiber, the surface char layer blocks the fiber with contacting fiber and inhibits the transmission of heat. The results also show that PCEPAM is not only a durable flame retardant but also a good charforming agent for cellulose [15].

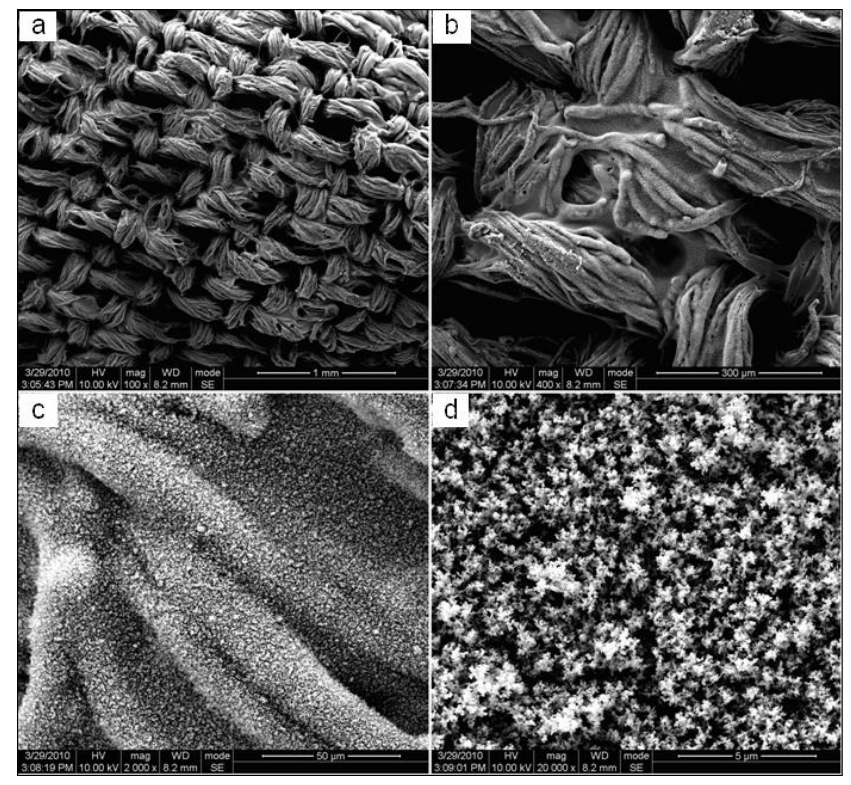

Fig. 8. SEM micrographs of the residual char of cotton fabrics treated with PCEPAM: $a-100 X ; b-400 X ; c-2000 X$; d-20000X

\section{CONCLUSIONS}

A Novel phosphorus-nitrogen flame retardant (PCEPAM) was synthesized via the reactions of a forming salt and dehydration. And a flame retardant agent with PCEPAM was prepared by acrylic emulsion. The cotton fabric was treated via pad-dry-thermo sol finishing using the coating. SEM micrographs show that the surface of fiber is covered by uniform and compact layered coatings. The LOI of FR fabric is more than $35 \%$ before washing when add-on $28.5 \%$. LOI still reaches to $28.6 \%$ after washing once, and LOI was $26.2 \%$ after washing 5 times. The results of SEM of residue after fabric burning and TGA all indicate that PCEPAM is an excellent charring agent for cotton.

\section{Acknowledgments}

This research is supported by the Talent Introduction Research Fund of Chengdu Technology University (2017RC018), the Key Project of Sichuan Education Department (12ZA005) and Key Cultivating Project of Chengdu Textile College (2014FZLKPY01). Authors are thankful to the Innovation Team for Wastewater of Chengdu Textile College (2014FZLKPY01).

\section{REFERENCES}

1. Horrocks, A.R., Kandola, B.K., Davies, P.J. Developments in Flame Retardant Textiles - A Review Polymer Degradation and Stability 88 (1) 2005: pp. 3-12. https://doi.org/10.1016/j.polymdegradstab.2003.10.024

2. Salmeia, K., Gaan, S., Malucelli, G. Recent Advances for Flame Retardancy of Textiles Based on Phosphorus Chemistry Polymers 8 (9) 319 2016: pp. 1-22.

https://doi.org/10.3390/polym8090319

3. Nguyen, T.M., Chang, S., Condon, B. Fire Self-Extinguishing Cotton Fabric: Development of Piperazine Derivatives Containing Phosphorous-Sulfur-Nitrogen and Their Flame Retardant and Thermal Behaviors Materials Science and Applications 5 (11) 2014: pp. 789-802. https://doi.org/10.4236/msa.2014.511079

4. Li, Q.L., Wang, X.L., Wang, D.Y. A Novel Organophosphorus Flame Retardant: Synthesis and Durable Finishing of Poly(ethylene terephthalate)/ Cotton Blends Journal of Application Polymer Science 117 (5) 2010: pp. 3066-3077. https://doi.org/10.1002/app.32074

5. Li, Q.L., Wang, X.L., Wang, D.Y. Durable Flame Retardant Finishing of PET/Cotton Blends Using a Novel PVA-Based Phosphorus-Nitrogen Polymer Journal of Application Polymer Science 122 (1) 2011: pp. 342-353. https://doi.org/10.1002/app.34182

6. Liu, W., Chen, L., Wang, Y.Z. A Novel PhosphorusContaining Flame Retardant for the Formaldehyde-Free Treatment of Cotton Fabrics Polymer Degradation and Stability 97 (12) 2012: pp. 2487-2491. https://doi.org/10.1016/j.polymdegradstab.2012.07.016

7. Li, Q.L., Huang, F.Q., Jiang, X.J. Preparation and Properties of a Washable Coating Flame-Retardant Fabric Indian Journal of Fiber Textile 41 (1) 2016: pp. 40-46.

8. Gao, M., Wu, F.C. Thermal Degradation of Flame Retardant Cotton Cellulose Advanced Materials Research 168-170 2010: pp. 380-383. https://doi.org/10.4028/www.scientific.net/AMR.168-170.380

9. Zhao, L., Wang, Y., Cao, D. Fragment-based Drug Discovery of 2-thiazolidinones as BRD4 Inhibitors: 2. Structure-based Optimization Jounal of Medicinal Chemistry 58 (3) 2015: pp. $1281-1297$. https://doi.org/10.1021/jm501504k

10. Mostashari, S.M., Moafi, H.F. Thermogravimetric Analysis of a Cellulosic Fabric Incorporated with Ammonium Iron (II)Sulfate Hexahydrate as a Flame-retardant Jounal Industry Textile 37 (1) 2007: pp. 31-42. https://doi.org/10.1177/1528083707078196

11. Wu, W., Yang, C.Q. Comparison of Different Reactive Organophosphorus Flame Retardant Agents for Cotton: Part I. The Bonding of the Flame Retardant Agents to Cotton Polymer Degradation and Stability 91 (11) 2006: pp. $2541-2548$.

10.1016/j.polymdegradstab.2006.05.010

12. Annakutty, K.S., Kishore, K. Polyphosphate Esters: 1. Condensation Polymers of Bisphenols with Aryl phosphorodichloridates: Synthesis, Characterization and Thermal Studies Polymers 29 (1) 1988: pp. 756-761. https://doi.org/10.1016/0032-3861(88)90096-1

13. Chen, D.Q., Wang, Y.Z., Hu, X.P. Flame-retardant and Antidripping Effects of a Novel Char-Forming Flame Retardant for the Treatment of Poly(Ethylene Terephthalate) Fabrics Polymer Degradation and Stability 88 (1) 2005: pp. 349-356. https://doi.org/10.1016/j.polymdegradstab.2004.11.010

14. Wang, C.S., Shieh, J.Y., Sun, Y.M. Phosphorus Containing PET and PEN by Direct Esterification European Polymer Jounal 35 (8) 1999: pp. 1465-1472. https://doi.org/10.1016/S0014-3057(98)00234-1

15. Carosio, F., Blasio, A.D., Cuttica, F. Flame Retardancy of Polyester and Polyester - Cotton Blends Treated with Caseins Industrial \& Engineering Chemistry Research 53 (10) 2014: pp. 3917-3923. https://doi.org/10.1021/ie404089t 